\title{
O projeto profissional de jovens das classes médias: orientações normativas e estratégias de inserção*
}

\author{
Marina Gomes Coelho de Souza ${ }^{1}$ e Lucia Rabello de Castro ${ }^{2}$ \\ Universidade Federal do Rio de Janeiro (Rio de Janeiro, RJ)
}

\begin{abstract}
A partir das transformações econômicas e sociais das últimas décadas, como a flexibilização e a precarização das condições de trabalho decorrentes da reestruturação produtiva, alteram-se os modos como os indivíduos planejam seu futuro profissional. Este artigo apresenta uma discussão sobre juventude e sua relação com o mundo do trabalho, em especial sobre a construção do projeto profissional no contexto da modernidade tardia, marcada pela imprevisibilidade e individualização das trajetórias. Pretendeu-se investigar de forma exploratória as principais orientações normativas, entendidas como valores centrais que norteiam as ações e alicerçam a construção de projetos profissionais. Foram realizadas entrevistas semiestruturadas com nove jovens universitários pertencentes às classes média e alta do Rio de Janeiro, de diferentes cursos superiores e em busca da primeira contratação profissional. Entre os principais resultados destacam-se as seguintes orientações normativas: a busca pela "qualidade de vida" e pela realização pessoal por meio do trabalho; a constante ascensão e qualificação profissional e a individualização das trajetórias de vida.
\end{abstract}

Palavras-chave: Projeto profissional, Inserção profissional, Juventude.

The professional project of middle-classes youth: normative guidelines and insertion strategies

From the economic and social transformations of recent decades, due to productive reorganization, and resulting in the flexibility and the precariousness of working conditions, changes the way whereby individuals plan their professional future. This article presents a discussion on the relation of the youth to the labour world, focusing on the construction of a professional project in the context of late modernity, characterized by the unpredictability and the individualization of life trajectory. It was aimed to research how the construction of professional project takes place, in its value dimensions and normative guidelines. Semi-structured interviews were carried out with nine university students from middle and upper social classes of Rio de Janeiro, Brazil, belonging to different fields of study and looking for their first professional contract. The main results include the following normative guidelines: the search for "quality of life" and personal fulfillment at work; the expectation of professional growth and constant qualification, and the individualization of labour trajectories.

Keywords: Professional project, Professional allocation, Youth.

\section{Introdução}

$\mathrm{O}$ trabalho tem ocupado historicamente lugar de centralidade na vida dos indivíduos, constituindo-se como importante fonte de interação coletiva, renda e proteção social. Entretanto, vem sendo modificado pelas transformações próprias da modernidade tardia, contexto no qual há um declínio da forma salarial institucionalizada, concentrada nas grandes empresas, e a ascensão de formas independentes de atuação trabalhista, acarretando no que Antunes (2005) denomina de uma 'nova morfologia do trabalho', que traz em seu bojo relações terceirizadas, contratos temporários, trabalhos part-time e informalização.

Nesse cenário, o grupo dos jovens é especialmente atingido, uma vez que, na atualidade, a dificuldade de inserção tem sido apontada como a principal condição de vulnerabilidade juvenil (Ibase/Polis, 2005). A juventude, entendida também da perspectiva da estrutura de relações sociais que se estabelece entre aquele que inicia uma inserção profissional ou se prepara fazê-lo, e aquele que já está posicionado nas condições de emprego. Caracteriza-se como um período de

\footnotetext{
* Artigo baseado na dissertação de mestrado de Marina Gomes Coelho de Souza (2013), desenvolvida no Instituto de Psicologia da Universidade Federal do Rio de Janeiro, sob a orientação da Dr. Lucia Rabello de Castro, com apoio da CAPES e FAPERJ.

1 Mestre em Psicologia pela Universidade Federal do Rio de Janeiro.

2 Doutora em Psicologia pela Universidade de Londres.
} 
consolidação da identidade e reconhecimento social, à medida que o jovem se legitima em espaços historicamente ocupados por adultos.

O sentimento de impotência decorrente da impossibilidade de visualização de uma saída possível para a inserção profissional faz com que os jovens vivenciem suas trajetórias como dominadas por forças que lhes são estranhas. Nesse sentido, a impotência pode levar à paralisia, resultando em fenômenos como a extensão da qualificação, a mudança ou abandono dos cursos universitários, entre outros (Korman Dib, 2007). Tais fenômenos, se analisados de modo superficial, tendem a ser compreendidos como individuais, sem que sejam considerados os aspectos socioeconômicos que repercutem em ações singulares.

Neste trabalho, buscamos verificar as orientações normativas que sustentam o agir dos jovens quando operam para se integrar no mercado de trabalho. O que chamamos aqui de orientações normativas se refere aos insumos valorativos que amparam o processo de inserção profissional. São, por exemplo, a relação com o futuro, o valor e significado do trabalho, assim como a forma como as condições macroeconômicas influenciam nas estratégias de inserção profissional e cujo efeito se apresenta nos modos como os jovens narram sua vida profissional, como constroem suas aspirações e na forma como agem na tentativa de se inserirem profissionalmente.

Por meio da pesquisa sobre as estratégias de inserção profissional adotadas acreditamos ser possível apreender as orientações normativas centrais do trabalho para os jovens, valores relacionados a um lugar social nos quais a ação é pautada, moldando projetos. Definimos valores ligados ao trabalho como crenças e/ou princípios relacionados às metas e recompensas que os indivíduos desejam alcançar. São hierarquicamente organizadas, de acordo com a importância que o sujeitos lhe atribui. Segundo Porto e Tamayo (2003) valores seriam "princípios ou crenças sobre metas ou recompensas desejáveis, hierarquicamente organizados, que as pessoas procuram através do trabalho e que orientam as suas avaliações sobre os resultados e contexto do trabalho, o seu comportamento no contexto de trabalho e a escolha de alternativas de trabalho" (p. 146).

\section{Juventude, trabalho e projeto profissional}

O trabalho é dotado de sentidos pelos jovens de forma complexa, variando entre sociedades e grupos sociais de acordo com o contexto e o tempo histórico, o que torna impossível a outorga de um único sentido, já que podem ser múltiplos e variados. No Brasil, sobretudo a partir dos anos 2000 pesquisas passam a se debruçar mais detidamente sobre a relação entre juventude e emprego, uma vez que os jovens passam a ser reconhecidos como o grupo mais intensamente atingido pelas mutações no mundo do trabalho (Corrochano, 2008). Segundo Bajoit e Franssen (2007), as expectativas e atitudes em relação ao trabalho se configuram como dimensões privilegiadas de análise ao se pensar a mutação dos referenciais entre os jovens no mundo contemporâneo, por terem centralidade no atual modelo cultural. "Apesar da diversidade de perspectivas nas análises sobre os modos como os jovens 'transitam' em direção à vida adulta, há um consenso em torno da diversificação e complexidade dos caminhos, bem como um reconhecimento de que a crise e as mudanças no mundo do trabalho teriam forte impacto nesse processo" (Corrochano, 2008, p. 5).

Processos históricos e sociais incidem sobre as formas singulares de experimentar "ser jovem", e a posição econômica deve ser considerada ao se problematizar o planejamento de um futuro para que se compreenda a maneira como se estrutura um projeto profissional, com determinados valores, significações, ou habitus. Este é entendido como um conjunto de disposições e padrões de comportamento, e modela as ações na forma de valores que norteiam a conduta. Nas palavras de Bourdieu (2007), "o habitus integra o conjunto dos efeitos das determinações impostas pelas 
condições materiais de existência" (p. 410). Neste sentido, o habitus se relaciona fortemente ao conceito de orientações normativas uma vez que igualmente organiza as práticas; sendo, entretanto, um conceito mais abrangente. Propomos o estudo com jovens pertencentes às classes média e alta do Rio de Janeiro por entendermos que esse segmento apresenta características específicas, uma vez que estão sujeitos a altos investimentos financeiros e tempo de qualificação, bem como com elevadas expectativas internalizadas no que se refere à inserção profissional, estabilidade e remuneração salarial.

Para Thome, Telmo e Koller (2010), as implicações das transformações da categoria social do trabalho atingem a subjetividade dos jovens, sobretudo, na forma de disseminação dos ideais do empresariado, como a cultura do desempenho, da excelência e da competição. A inserção no mercado é atravessada pela valorização da qualidade, produtividade, criatividade, polivalência e versatilidade, e aos jovens cabe corresponder a tais ideais. Segundo Gaulejac (2007), "As empresas, e suas necessidades, começam a ditar as prioridades, os valores e as imagens ideais da nova subjetividade da classe média" (p. 10).

Este perfil do trabalhador ideal se reflete no conceito bastante controverso de "empregabilidade", ou seja, a capacidade individual de conseguir emprego ou manter-se empregado. Como salienta Antunes (1999), anteriormente a preocupação com a obtenção e condições de um emprego era socialmente compartilhada, cabendo ao Estado grande parte desta responsabilidade. No entanto, atualmente passa a ser cada vez mais individualizada, ancorada nos ditames da busca pela infindável qualificação e desenvolvimento de competências. As novas exigências demandam profissionais cada vez mais flexíveis, disponíveis aos interesses coorporativos e hiperqualificados. A extensão do período de qualificação tem gerado, sobretudo na classe média e alta, um aumento do tempo de escolarização com efeitos sobre a subjetividade dos jovens.

Korman Dib e Dias (2004) afirmam que há, para os jovens, uma dissociação entre a ação sobre o próprio destino e a ação sobre o destino da sociedade. Soma-se a isso o fato de que a nova configuração político-econômica reduz as formas de seguridade social e, pautado na lógica do liberalismo, o jovem se vê responsabilizado pelo sucesso ou fracasso, sem que seja trazido à luz o contexto sociocultural no qual a trajetória individual se insere. O problema da inserção profissional passa a depender de cada um, desconsiderando a estrutura social, ou seja, há uma instrumentalização do campo educacional em favor do capitalismo flexível. A educação passa a ter como principal tarefa a formação de um banco de reserva de sujeitos competentes e disponíveis, dispostos a galgar seu posto no mercado, e a qualificação se apresenta como forma de estarem em "vantagem" em relação aos demais, a lógica da competição das empresas é transferida e assimilada como um valor individual.

A trajetória profissional percorrida por um sujeito, geralmente iniciada com a escolha de uma profissão, por sua vez relacionada ao progresso e ascensão social, foi tradicionalmente chamada de carreira. Entretanto, como nos aponta Tolfo (2002), tal modelo de trabalho esteve pautado na noção de estabilidade, na qual trabalho, carreira e emprego eram percebidos como sinônimos. Segundo a autora, caminha-se para uma realidade na qual a possibilidade de uma carreira estável configura-se como restrita a um pequeno número de pessoas. Apesar dessa nova configuração macroeconômica, Bajoit e Franssen (2007) afirmam que o modelo tradicional do "emprego" ainda é bastante presente e desejado por muitos jovens, embora se torne cada vez mais difícil de praticar.

Uma vez que os mecanismos de regulação social deixam de oferecer referenciais estáveis e previsíveis, as trajetórias profissionais adquirem o selo do caótico, com diversas rupturas e momentos de descontinuidade entre as situações ocupacionais. Tais mudanças "afetam as chances das carreiras sólidas que se constituíam duradouramente por toda vida ocupacional” (Guimarães, 2006, p. 175). Para Malvezzi (1999) o modelo de carreira tradicional possibilitava um planejamento 
linear e ascendente dentro do sistema hierárquico da empresa. Já o modelo emergente é irregular e imprevisível, tanto no que se refere à remuneração, quanto às mudanças entre posições dentro de uma empresa, ou em diferentes instituições, ou ainda como trabalho autônomo. As trajetórias perdem o sentido de carreira organizacional tradicional, pois já não se pode pensar a relação com o trabalho como um percurso coerente e sequencial. Resultado da flexibilização de contratos, horários, salário e funções, o novo cenário altera o significado que os sujeitos atribuem ao trabalho e à forma como se relacionam com seus projetos profissionais.

A partir de pesquisas que questionam a validade de construção de um projeto numa época marcada pela imprevisibilidade, e constatam a dificuldade dos jovens em converter em ação as múltiplas possibilidades de escolha, (Corrochano, 2008; Korman Dib, 2007; Juncken, 2005; Monteiro, 2011), objetivou-se conhecer as orientações normativas norteadoras da elaboração de um projeto profissional e estratégias de ação adotadas na efetivação deste projeto.

\section{Estratégia metodológica: os jovens e suas narrativas sobre o projeto profissional}

Desenvolvemos esta pesquisa privilegiando a aproximação com jovens que estivessem vivenciando o processo de inserção no mercado de trabalho, e que se voluntariaram a depor sobre seu cotidiano. Dada a complexidade, sutileza e dinamismo das manifestações da subjetividade humana, optou-se pelo método qualitativo e exploratório, uma vez que o foco recaiu sobre as particularidades de um fenômeno. Segundo Minayo (2004), os métodos qualitativos se preocupam com o nível de sentidos, significados, motivos, crenças e valores relacionados a seu objeto de estudo.

Para acessar a complexidade das narrativas sobre os projetos profissionais utilizamos entrevistas semiestruturadas, com duração de cerca de uma hora, com alunos oriundos de diferentes cursos universitários. A entrevista com o formato semiestruturado se caracteriza por uma junção da entrevista aberta, na qual o entrevistado discorre livremente sobre o tema proposto, e a entrevista estruturada, na qual as perguntas são previamente formuladas. Sendo assim, a partir dos objetivos de pesquisa e imersão na literatura sobre o tema, algumas perguntas foram elaboradas e deram origem a um roteiro com temas pré-estabelecidos. $\mathrm{O}$ levantamento teórico nos fez atentar especialmente para as seguintes temáticas: a relação dos jovens com o futuro; a imprevisibilidade que marca as condições de vida no contemporâneo; a multiplicidade de opções profissionais; o planejamento do futuro profissional; as estratégias de inserção profissional e os retornos esperados do trabalho. No entanto, o roteiro não foi utilizado como limitador para as entrevistas, mas as perguntas funcionaram como disparadoras e os entrevistados puderam abordar temas não estabelecidos, mas que julgassem relevantes para esclarecer sua posição.

As entrevistas individuais abordaram aspectos relacionados à vida acadêmica e experiências profissionais dos jovens: estágios, pequenos trabalhos, remunerados ou não; projetos de pesquisa ou extensão; e demais atividades relacionadas à profissão ou formação. Buscamos captar principalmente o modo como tais vivências impactaram suas trajetórias e participaram da construção de seus projetos profissionais.

Após a transcrição do material coletado nas entrevistas, realizou-se intensa leitura e imersão nas narrativas, investigando a construção discursiva dos sujeitos. O discurso é aqui entendido como constitutivo dos sujeitos, dos objetos de conhecimento, das relações sociais e das formas de construção do "eu". Assim, o discurso não só representa o mundo, mas o significa ao mesmo tempo em que o constitui. Trata-se de uma forma de ação do sujeito, na medida em que atua na 
construção do mundo que o cerca a partir da interlocução com os outros, na experimentação e na vivência. Consideramos que ao explorar a narrativa dos sujeitos sobre sua inserção seremos capazes de nos aproximar da significação de tal prática.

\begin{abstract}
"Assumir que o discurso é uma forma de ação tanto quanto de representação implica uma concepção da linguagem como algo não transparente e da comunicação, como um espaço ou uma instância onde ocorre, de fato, uma disputa de posições, uma luta por poder. Implica, pois, no reconhecimento do conteúdo ideológico da linguagem e do discurso, e no uso estratégico da comunicação. Em outra perspectiva, entender o discurso como prática social implica em reconhecer que discurso e estrutura social existem em relação dialética e que o discurso contribui para a constituição de todas as dimensões da estrutura social" (Korman Dib \& Dias, 2004, p. 7).
\end{abstract}

A análise pressupôs a compreensão do sujeito como construtor e construído pelo social, e a noção de que nenhuma fala é transparente ou neutra, mas comporta o contexto no qual se localiza, explicitando formas de relação com o mundo. Recorremos à narrativa, pois consideramos que o sujeito-narrador, à medida que se remete a um conjunto de códigos e signos compartilhados, também se reconhece como pertencente à determinada comunidade.

A partir da sistematização do material, do cotejamento com a literatura e da análise das narrativas, identificaram-se sentidos recorrentes e predominantes nas falas dos jovens, que deram origem a categorias. A categorização consistiu na diferenciação, classificação e agrupamento das unidades básicas, utilizando-se como critério de definição os sentidos predominantes, ou seja, divisões temáticas. Tais grupos de sentidos representaram o que se denominou de orientações normativas, e se referem aos valores que sustentam a construção do projeto profissional.

Participaram desta pesquisa nove jovens universitários, cursando os últimos períodos da graduação, sendo quatro homens e cinco mulheres, entre 22 e 29 anos, residentes em bairros da Zona Sul do Rio de Janeiro, que apresentam as maiores colocações segundo o Índice de Desenvolvimento Humano (IDH) da cidade. A renda familiar de todos superou dez salários mínimos mensais, o que os posiciona como pertencentes às classes média e alta, segundo o Instituto Brasileiro de Geografia e Estatística - IBGE (Waiselfisz, 2007). Dentre os jovens entrevistados, oito residiam na casa de familiares, e um com amigos. Em relação à atuação profissional, no momento da realização das entrevistas, três estavam estagiando na área profissional, três estavam empregados na área de atuação, um havia aberto seu próprio negócio e dois estavam procurando colocação. Os jovens estão distribuídos entre os seguintes cursos universitários: Bacharelado em Canto (1), Administração de empresas (3), Publicidade e Propaganda (1), Engenharia Civil (1), Engenharia de Produção (2) e Hotelaria (1), todos nas fases finais da graduação.

Embora a pesquisa possua o recorte de classe, muito mais do que delimitar uma renda familiar, buscamos jovens cuja identidade comportasse os valores das classes médias e altas. Levamos em consideração, além da renda familiar, aspectos como o local de residência e a ocupação dos pais. Assim como afirma Carreteiro (2007), consideramos que o local de residência tem influência nas formas de socialização, nos valores que são transmitidos aos jovens, por meio da família ou da escola, bem como na construção do projeto profissional propriamente dito. Além disso, viabiliza ou limita as possibilidades de inserção.

É importante frisar que a categoria juventude é aqui utilizada de forma ampliada, não nos limitando à classificação utilizada pelo IBGE de até 24 anos (Waiselfisz, 2007). Isto porque consideramos que no contexto atual a inserção profissional se dá cada vez mais tarde, principalmente para o segmento das classes médias e alta, resultado do aumento das exigências de qualificação 
e dificuldade de inclusão no mercado de trabalho (Korman Dib, 2007). Os nomes utilizados são fictícios, visando preservar a identidade dos entrevistados.

\section{Análise das entrevistas: as orientações normativas do projeto profissional}

As orientações normativas, reveladas a partir da narrativa dos jovens, os mobilizam para a ação e os balizam na construção de seus projetos profissionais. Corroborando a literatura sobre a temática, identificamos por meio da fala dos jovens habitus de classe claramente marcados que se repetem, próprios de um lugar social, refletidos em orientações normativas que se traduzem nas seguintes categorias de análise: a busca pela qualidade de vida e pela realização pessoal por meio do trabalho; a constante ascensão e qualificação profissional e a individualização das trajetórias de vida.

\section{A busca pela "qualidade de vida" e pela realização pessoal por meio do trabalho}

No que se refere aos valores vinculados à vida profissional, a 'qualidade de vida', enquanto objetivo a ser alcançado, tem sido massificada como um ideal contemporâneo, contrapondo-se à ideia de trabalho exclusivamente calcada em sua dimensão de subsistência. Em relação ao retorno financeiro, a qualidade de vida surgiu no discurso dos jovens entrevistados de duas formas. A primeira delas se refere à sua priorização em detrimento de altos ganhos financeiros, uma vez que os jovens afirmam desejar ter qualidade de vida em primeiro lugar, ainda que isso possa representar a renúncia a um ganho monetário maior. Como exemplificado na fala que se segue:

"Financeiramente falando não tenho pretensão de ser um cara super milionário, primeiro de tudo quero a minha qualidade de vida" (Renato, 24 anos, Administração).

No segundo caso, a qualidade de vida e a remuneração aparecem como elementos paralelos, como condição uma para a outra, o que é explicitado em relatos nos quais os jovens afirmam desejar a qualidade de vida, caracterizada como possibilidade de obtenção de bens e serviços propiciados pelo poder econômico.

"Mas eu almejo ganhar o que eu espero, na qualidade de vida, ganhar dinheiro, poder ir viajar" (Gustavo, 23 anos, Engenharia de Produção).

Além da dimensão financeira, o ideal da qualidade de vida se alia a outros determinantes, tais como a carga de trabalho, a distância entre a casa e o trabalho e a liberdade. Trazemos a seguir trechos nos quais os jovens discorrem sobre o trabalho ideal nos quais citam tais elementos.

"Perto de casa, com certeza. Ter qualidade de vida, acho importante, você não pegar três horas de trânsito. De carga de horária nem me ligo muito, pode até ser um pouco maior, mas se eu tiver perto de casa, é o mais importante" (Laiz, 24 anos, Administração).

Laiz nos fala da importância da qualidade de vida de um modo bastante objetivo, relacionada a aspectos do cotidiano de trabalho.

"Um trabalho com mais liberdade. Acho que esse lance de trabalhar 8 horas por dia, todo dia, pra você faltar pra ir ao médico é um drama, nossa, preciso avisar meu chefe que vou ao médico. Uma coisa meio mal, entendeu"? (Luana, 22 anos, Publicidade e Propaganda). 
A questão da liberdade como parte da qualidade de vida se repete na fala dos jovens. Tratase de uma variável importante que passa a integrar o discurso para além da ideia do dinheiro como prioridade. Os jovens valorizam a possibilidade de ter autonomia no trabalho, bem como desfrutar de momentos de lazer.

A busca pela qualidade de vida emerge como um dos principais valores almejados pelos jovens no que se refere à vida profissional. Tal orientação normativa parece ser um elemento central em torno do qual outros gravitam por terem com ela forte relação, constituindo-se como referencial central do que é valorizado pelos jovens em termos profissionais. As entrevistas revelam que o sucesso não é almejado apenas em termos financeiros, mas comporta valores complementares que apontam para o modo como o trabalho pode ser vivido e significado, não como um assujeitamento, mas como meio de assegurar um espaço social.

O discurso dos jovens pesquisados está carregado pela ambição de conseguirem satisfação no trabalho. Quando convidados a pensar sobre o trabalho ideal, bem como quando indagados sobre seus projetos, relatam a importância de que lhes tragam realização pessoal, na medida em que se sintam úteis e felizes em suas atividades. Não parecem estar dispostos a grandes sacrifícios em nome de uma carreira, mas desejam uma profissão que, além do sustento, lhes proporcione prazer e realização.

"Se eu mantiver o meu foco, eu sei que eu tenho um futuro, não brilhante, não vou ficar milionária, mas eu vou ser feliz no que eu faço, vou estar satisfeita com o que eu faço" (Laiz, 24 anos, Administração).

A fala apresentada nos remete à questão da felicidade no trabalho, presente em diversas entrevistas e fruto de uma lógica sociocultural na qual o trabalho deve, além de proporcionar renda, ser fonte de satisfação pessoal.

"Fazer uma coisa que eu relativamente goste de fazer, que dê um retorno pra mim e até pra sociedade também. Financeiramente compatível, que eu mereça ganhar. Não quero nada exorbitante, mas também não quero ser injustiçado. E lógico, ser um gestor que o pessoal respeite, que seja de referência. Acho que isso vale mais do que você ganhar qualquer bônus ou PL no final do ano. Os empregados que trabalhem com você gostem de você, tenham prazer de trabalhar com você, acho que isso deve ser gratificante" (Renato, 24 anos, Administração).

Renato destaca quão fundamental é a questão do retorno para ele mesmo e para a sociedade. Para o jovem, a aceitação e o reconhecimento do grupo de trabalho são fatores importantes para que haja satisfação no ambiente de trabalho. Os entrevistados ressaltaram a importância de se fazer o que gosta, aliando a busca pelo retorno financeiro à necessidade de satisfação profissional, o que passa a ser encarado como um imperativo contemporâneo. A remuneração se inclui como elemento importante para a satisfação geral relacionada ao trabalho, fortemente relacionada à lógica do merecimento.

É válido ressaltar que as falas partem de universitários de classe média e alta que, em sua maioria, estão ainda estagiando e obtêm auxilio financeiro de familiares, e que a questão da subsistência não se apresenta ao longo de suas histórias como parte de sua condição. A preocupação com a realização no trabalho e com a qualidade de vida emergem, assim, em primeiro plano.

Gaulejac (2007) aponta que esse sujeito ideal do novo projeto de sociedade do mundo produtivista deve ser capaz de resolver problemas complexos, assumir riscos, suportar estresse e colocar todas as suas qualidades a serviço da rentabilidade. Neste sentido, as relações privadas são também invadidas pelo pragmatismo, utilitarismo, competição, rentabilidade, desejo de ganho e poder. $\mathrm{O}$ autor assinala que o modo gerencialista de administração da vida se apresenta de forma 
acentuada no seio das famílias. Intensos investimentos são realizados a fim de que os filhos possam estar preparados na luta por um lugar.

\section{A constante ascensão e qualificação profissional}

A postergação do ingresso dos jovens no mercado, a redução da jornada de trabalho dos adultos, ampliação do ciclo educacional e o aumento da expectativa de vida geraram possibilidades inéditas para o mundo do trabalho. Para Pochmann (2012), as transformações do último século passam a redefinir categorias básicas, tornando antiquados os sistemas atuais de educação e formação profissional. Segundo o autor, a sociedade pós-industrial abriu novas perspectivas para a valorização do trabalho humano que vão além daquelas essencialmente ligadas à sobrevivência.

Ainda que tenha havido um aumento da flexibilização dos postos de trabalho e a carreira esteja em um momento de reformulação, os jovens ainda manifestam o desejo de estabilidade com os contornos de um emprego e permanência em uma mesma empresa, desde que nela vislumbrem um crescimento profissional. Tal fenômeno reflete a aspiração pela constante ascensão na profissão, pois aos jovens interessa contínuo desenvolvimento e aprimoramento. No entanto, todos revelam estar abertos a mudanças em busca de melhores oportunidades, e a menção de fidelidade à empresa não está presente nas narrativas.

"E um lugar também que te dê oportunidade de crescer. Não adianta ficar 15 anos numa empresa no mesmo lugar. Ninguém hoje em dia aguenta” (Laiz, 24 anos, Administração).

Estabilidade e liberdade são elementos presentes nas entrevistas, ainda que cada entrevistado faça uma opção singular da importância dada a cada dimensão. Embora a busca pela estabilidade seja dominante, nota-se considerável desejo de flexibilidade, o que indica a conformação subjetiva "flexível" como sendo adequada e moldada por nossa contemporaneidade fluida.

"Eu não quero estar preso, eu não quero ter um contrato com um cara que ele compra uma parte da minha vida por tantos reais por mês. Não me sinto bem assim. É assim que a sociedade se organiza hoje" (Guto, 23 anos, Engenharia de Produção).

O relato acima parte de uma lógica na qual a autonomia é preconizada em detrimento de uma vida guiada pelo assujeitamento à vida laboral. Guto afirma não se identificar com a forma de organização social baseada em contratos de trabalho e carga horária definida. Se comparado aos demais relatos, trata-se de um posicionamento bastante particular, embora tenhamos notado uma tendência geral à valorização de novas formas de trabalho, como demonstrado na fala que se segue.

"Ah, um trabalho que você tivesse a liberdade, claro e responsabilidade, de você trabalhar na empresa, você ir lá, conversar com as pessoas que trabalham com você, mas que você pudesse também fazer da sua casa. Um trabalho com mais liberdade" (Luana, 22 anos, Publicidade e Propaganda).

Ressaltamos aqui a fala de uma jovem que enfatiza a liberdade e as possibilidades que um trabalho mais flexível pode oferecer. Concordamos com Antunes (2005) ao ressaltar que esse modelo de trabalho, ainda que possibilite maior liberdade individual e autonomia, geralmente emerge acompanhado da precarização dos direitos básicos do trabalhador. Evidencia-se que este processo de transição vem sendo experienciado pelos jovens de diferentes maneiras. 
"Eu espero ser bem sucedida, sei lá. Eu queria fazer carreira em algum lugar, entendeu? Porque quando você faz a tendência é você ir crescendo dentro da empresa. Eu espero tá bem sucedida, feliz, muito feliz no meu emprego" (Luana, 22 anos, Publicidade e Propaganda).

A fala revela um desejo de satisfação que se pauta na construção de uma carreira, no entanto tal projeto, entendido como "ser bem sucedida", não parece contemplar aspectos de uma experiência vivida que o sustentaria. Muito mais baseado em projeções e "tendências", o futuro parece carecer de conhecimentos experimentados em práticas anteriores. Em suas diversas nuances, o "crescimento profissional" é uma orientação presente com unanimidade nas falas dos entrevistados, revelando uma expectativa no que concerne à progressão na carreira, um desejo de constante elevação dos postos de trabalho a serem ocupados e reconhecimento.

É importante perceber que questionados sobre suas metas profissionais, bem como sobre os meios pelos quais buscariam alcançá-las, as falas não explicitam estratégias ou ações que concretizarão tais desejos. Por mais que anseios estejam presentes, os modos de efetivação se apresentam de forma vaga e superficial, o que sugere desconhecimento dos mecanismos que regem as dinâmicas de ascensão no mercado de trabalho, além de poucas experiências profissionais, corroborando o encontrado por Korman Dib (2007).

A constante qualificação também é um valor norteador das aspirações profissionais dos jovens entrevistados. Imersos em um contexto de competição e buscando formas de ascensão e diferenciação, os jovens relatam o desejo de continuar se especializando, por meio de pós-graduações, intercâmbios ou especializações. É importante ressaltar que as orientações normativas aqui assinaladas se relacionam e se nutrem, a exemplo da contínua formação, que se relaciona diretamente ao desejo de crescimento profissional. Sendo assim, como a qualificação é amplamente compreendida como uma forma de valorização profissional, é utilizada como estratégia para o crescimento na carreira.

O título universitário torna-se um valor e condição para a inserção no trabalho de jovens das classes médias e o diploma aparece como elemento que garantiria a possibilidade de um futuro repleto de oportunidades. Para Neves (2006), o discurso da "qualificação-redentora" tende a apagar os diferentes modos de organização social e econômica, ocultando a dimensão política e os jogos de interesse que permeiam o tema.

É importante ressaltar que a relação entre a alta qualificação e a boa colocação no mercado de trabalho nem sempre se confirma. Isso porque a demanda por postos que exigem vasta especialização não cresce na mesma proporção que a formação de jovens com nível superior. Por consequência, não são raras as vezes nas quais jovens não ocupam lugares no mercado de trabalho que sejam condizentes com sua alta qualificação, tornando-se assim sobre-qualificados para os cargos que ocupam (Oliveira, 2011). Como nos assinala Tanguy (1999), ainda que experiências individuais e estudos estatísticos corroborem tal relação, trata-se de uma união socialmente produzida e historicamente localizável. A constatação de que jovens menos diplomados estão mais suscetíveis ao desemprego, assegurando a relação entre qualificação e empregabilidade, não deve ocultar o fato de que o aumento geral dos níveis de qualificação não tem impedido o aumento das taxas de desemprego entre os jovens mais diplomados.

Percebe-se, no discurso desses jovens, a relativização da importância do conhecimento adquirido nos bancos das universidades. Ainda que o diploma seja reconhecido como importante instrumento para a inserção profissional, é muito mais valorizado como forma do que como efetivamente gerador da principal condição necessária ao dia-a-dia no mundo do trabalho.

"Então isso é importante pra gente crescer profissionalmente. Então eu tenho que me formar pra ter um currículo pra que as pessoas que não me conhecem aceitem me ouvir" (Guto, 23 anos, Engenharia de Produção). 
Na fala em questão, o jovem se vê impelido a terminar uma faculdade não pelo conhecimento que lhe será transmitido, que ele acredita ser capaz de obter por outros meios mais eficazes, mas pela necessidade de apresentar o diploma a terceiros. $\mathrm{O}$ jovem acredita que, ao possuir o diploma de nível superior, será também detentor de credibilidade e, por consequência, poderá acessar um maior número de pessoas por meio do seu trabalho, ainda que este mantenha frequentemente pouca relação com o conhecimento adquirido na universidade. Segundo o entrevistado, o fato de não possuir o título de nível superior limitaria suas oportunidades e o desvalorizaria perante os demais. Tal posicionamento explicita a importância e o valor de um título superior para os jovens, valor passado pelas famílias como modo de ascensão ou manutenção de um status sociolaboral. Há uma forte ideia de vinculação entre formação superior e emprego, e a análise das falas evidencia a dificuldade destes jovens em visualizar qualquer profissão que não envolva a universidade como passagem obrigatória.

"Não posso dizer que tenho paixão por administração, eu faço mais pela profissão, ser formado e ter um emprego" (Douglas, 26 anos, Administração).

Os entrevistados denunciam o sistema de ensino universitário como insuficiente na preparação profissional, bem como ultrapassado no que se refere às formas de transmissão do conhecimento acadêmico. Segundo eles, seria um modelo educacional apoiado em métodos fragmentados, especializados e setorizados de ensino.

“[...] tem algumas coisas que você aprende muito na teoria que você rasga tudo que na prática não vai usar nada. Falta realmente preparar pra vida, pro mundo. Tem professor que cobra você saber uma tabela absurda, ridículo, só numa faculdade, na vida você não vai pegar aquela tabela e gravar a vida toda. Mas é fácil falar a faculdade te prepara pra vida, mas será mesmo?" (Carla, 23 anos, Engenharia Civil).

Expõe-se uma insatisfação dos alunos no que se refere à preparação para a prática profissional, pois afirmam serem exigidos conteúdos acadêmicos que na vida profissional não serão utilizados, enquanto outros aspectos do exercício profissional seriam negligenciados. As falas revelam a expectativa de que tudo deveria estar assegurado para eles, uma vez concluído o curso superior: a inserção profissional e o domínio prático/teórico. A desqualificação da graduação se dá quando esta é desmitificada pelo fato de não assegurar um imediatismo na inserção laboral, assim como uma localização restrita às questões práticas da vida. Os jovens são confrontados com as defasagens e faltas presentes entre a realidade e o conhecimento adquirido.

Os discursos midiáticos muitas vezes, além de informar, passam a naturalizar essas mutações no mundo do trabalho. São incentivados o apelo e a competição, além da ideia de que a qualificação constante se reverterá em uma inserção profissional segura, oferecendo duvidosas recomendações de como os jovens devem proceder a fim de alcançarem o sucesso (Korman Dib, 2007).

\section{A individualização das trajetórias de vida}

No que tange à inserção profissional, a independência, tanto financeira quanto afetiva, enquanto valor a ser alcançado, se configura como reflexo do processo de individualização, fenômeno que atravessa a construção das trajetórias juvenis. Muito mais do que baseada em dados da realidade econômica ou social, a expectativa do jovem aparenta ser autocentrada, ou seja, os parâmetros para seu ganho salarial estariam vinculados ao merecimento pessoal segundo sua própria visão; mais do que a aspectos sociais, econômicos ou do mercado de trabalho. Os desejos e ações dos jovens se apoiam, sobretudo, em um "eu" que deseja, sonha, age; sem que sejam 
percebidos ou relatados aspectos sociais que possam determinar o processo de subjetivação, e como esse "eu" emerge a partir das determinações de sua condição de existência. Nota-se aí a clara expressão da individualização vivenciado por esses jovens.

"O trabalho ideal é fazer o que você gosta. O trabalho chato pra você pode ser bom pra mim. Eu conheço gente que trabalha vinte horas por dia e é feliz. Tem gente que vê de fora e acha o cara louco. Mas cada um é cada um e cada um gosta de uma coisa. E eu acho que o trabalho tem que se realizar pra si e não pros outros. Tem cara que é pesquisador, gosta de pesquisar, passa o dia dentro do laboratório, tem cara que acha que ele é maluco, mas ele está se satisfazendo. Não ganha muito, mas gosta do que faz. Acho que o principal é isso, fazer o que você gosta. Claro que é difícil, uma empresa que você gosta, tentar estar num lugar que você se sinta bem. Isso pra mim é o primordial" (Douglas, 26 anos, Administração).

Apreende-se da fala dos jovens que há um "eu" que deve ser descoberto e preservado, ainda que seja evidente que tal subjetividade reflete os valores de toda uma classe; a individualização exacerbada traz elementos ao trabalho, como observado na fala acima, enquanto um valor individual e que portanto "tem que se realizar pra si e não pros outros".

"Que eu goste de fazer. Estando com um grupo de pessoas capacitadas e motivadas pra executar a função. Sempre tentar tirar delas o melhor possível, preocupado com elas também. Como que elas tão. Não só profissionalmente, humanamente também. Saber como que elas tão em casa, como estão os filhos delas, como que foi final do mês, no dia a dia mesmo, se tá namorando se não tá. Isso tudo faz parte de um processo que o empresário tem que saber. O cara que se forma tem que saber lidar. Acho que todo mundo gosta de sentir que alguém tá se preocupando com você. Acho isso fundamental" (Renato, 24 anos, Administração).

Já a fala de Renato traz a questão do grupo para o trabalho. No entanto, é importante notar que o jovem não se coloca como incluído no grupo, mas sim numa posição de liderança na qual seu papel em relação aos demais seria o de "tentar tirar delas o melhor possível". Consideramos esse mais um exemplo da extrema valorização do "eu", já que eles não se veem como parte de um conjunto ou categoria de pessoas, sejam jovens, estudantes ou universitários. Suas falas estão constantemente relacionadas a uma trajetória que parece ser traçada e vivenciada de forma bastante solitária e individualizada. As estratégias para a inserção profissional denunciam um reducionismo subjetivista, visto que os relatos apontam para a crença de que o sucesso ou fracasso está condicionado exclusivamente ao esforço individual (Ribeiro, 2010).

Para Valore e Selig (2010), o processo de individualização, e consequente responsabilização dos jovens pela situação de desemprego ou precarização do trabalho, é evidenciado quando os próprios jovens classificam tal situação como decorrente da falta de qualificação, iniciativa ou experiência dos colegas, desconsiderando o contexto econômico, histórico, político e social. $\mathrm{O}$ discurso dos jovens está permeado pela lógica de que, caso estejam adequadamente preparados, seu lugar no mercado de trabalho estará garantido. Esvazia-se o trabalho como projeto coletivo e torna-se meio individual de consumo e autorrealização. Como nos aponta Giroto Guedes (2007), os efeitos de tal configuração do trabalho são vivenciados pelos sujeitos de forma solitária, resultando em sentimentos de não pertencimento e insegurança.

Para Castro (2011), a formação dos jovens se dá em uma perspectiva individualizada, na qual cada um é responsável por si na medida em que desenvolve seu potencial. A privatização do lugar social do jovem como local de aperfeiçoamento de capacidades individuais se deu por meio 
de regimes de institucionalização centrados na capacitação para o trabalho. Segundo a autora, o modo de subjetivação calcado no individualismo resulta na disjunção entre o singular e o coletivo.

Nossos resultados corroboram a discussão levantada por Bajoit e Franssen (2007), que apontam uma importante mudança no lugar ocupado pelo trabalho na vida dos indivíduos. Deixa de ser compartilhado coletivamente, modo no qual o sujeito se via imerso em um projeto de sociedade, e passa a ser valorizado de modo individual, como essencial para o desenvolvimento de um projeto particular. Nesse contexto, conforme aponta Antunes (1999), o discurso da "empregabilidade" e da "qualificação", deixa recair sobre o sujeito a responsabilização por problemas da ordem da organização do sistema socioeconômico.

\section{Considerações finais}

Consideramos que por meio do relato de suas trajetórias os jovens puderam manifestar o modo como se relacionam e concebem o mundo do trabalho, descortinando o valor que lhe é atribuído. A elaboração de um projeto profissional resulta de uma trajetória pessoal moldada por múltiplas determinações, sejam elas a dinâmica familiar, a vida acadêmica/escolar e os grupos de pertencimento. A análise dos projetos profissionais aqui destacados buscou identificar e explicitar as diferentes orientações normativas que norteiam e/ou influenciam jovens das classes médias nesse processo. É importante frisar que os arranjos, conflitos e contradições presentes no percurso determinarão as possibilidades e limites da construção de um projeto, o qual contempla, além do próprio planejamento, sua gestão e realização (Ribeiro, 2010).

Identificamos orientações normativas que norteiam a inserção no mercado de trabalho desde sua constituição, bem como em sua dimensão prática. A primeira delas, o imperativo da busca pela qualidade de vida e autorrealização parece orientar as escolhas profissionais de muitos dos jovens entrevistados, considerado um aspecto indispensável no planejamento de um futuro trabalho. A qualidade de vida significa para esses jovens a liberdade de investir em outras áreas de suas vidas como a esfera familiar e social, uma vez que o assujeitamento ao trabalho não é valor difundido entre eles.

Consideramos, assim como Gaulejac (2007), que a partir das transformações da classe média, consequência da nova configuração econômica e social, os valores da autodisciplina e autonegação foram substituídos pelo consumo e pela perda da importância anteriormente atribuída à acumulação do capital e ao trabalho duro. A ideia de que com esforço e disciplina se alcançaria o progresso perdeu sentido, uma vez que o sucesso pessoal passou a ser compreendido como dominado por variáveis que escapam ao controle do sujeito.

Os jovens relataram ser de grande importância para a vida profissional a realização pessoal, traduzida em falas como "sentir-se útil no trabalho" e "gostar do que se faz". A partir da fala dos entrevistados, duas perspectivas em relação ao trabalho são identificadas: a primeira delas se refere à dimensão instrumental, relacionada aos ganhos financeiros; a segunda, a uma expectativa expressiva, referente ao status social e satisfação pessoal. Os jovens afirmam que a realização no trabalho é tão importante quanto o futuro salário.

A constante qualificação e o crescimento profissional são elementos, segundo os jovens, capazes de promover a ascensão sociolaboral. São frequentes as referências à necessidade de continuada qualificação como meio de promoção na carreira, o que nos leva a constatar que o crescimento e a qualificação são, para os jovens, meios de efetivarem o desejo de seguirem galgando maiores postos no mercado de trabalho, e de se sentirem mais valorizados e socialmente reconhecidos.

A análise das entrevistas revela que as trajetórias são vivenciadas de modo individualizado, priorizando tudo aquilo que é da esfera do pessoal, o que torna evidente o valor que atribuem 
à independência. Não estão presentes nas falas dos jovens aspectos ou determinações sociais que poderiam incidir sobre suas histórias: parecem estar sujeitos a um reducionismo subjetivista no qual há a crença de que o sucesso será conquistado exclusivamente pelo esforço individual, herança dos processos de individualização a que estão submetidos. A ideologia da individualização tende a mascarar relações de dominação, já que restringe problemas coletivos à esfera pessoal, invisibilizando obrigações sociais do Estado em gerar postos de trabalho e condições de empregabilidade. Os jovens entrevistados desconhecem uma organização do trabalho construída pelo coletivo, a partir de referências como categorias profissionais ou sindicatos.

A imprevisibilidade da contemporaneidade parece contagiar os jovens no momento de construção do futuro profissional, já que não relatam preocupação com o planejamento do amanhã. Afirmam não se programar para longo prazo, o que nos leva a pensar que o não-planejar se constitui como um modo de se relacionarem com as incertezas do devir. Os jovens se encontram em um contexto no qual são levados a construir suas biografias em um território que não oferece garantias sobre o futuro. A experiência de flexibilização das relações torna as vivências episódicas e fragmentárias, que são introjetadas pelos jovens e revelam-se no discurso que enaltece as liberdades individuais.

Os jovens que se apoiam em experiências profissionais anteriores, como estágios e pequenos trabalhos, têm clareza dos limites e possibilidades concretos de sua formação, e parecem ser aqueles com maior capacidade de adotar ações na direção da viabilização de seus projetos. Para esses, ainda que o diploma seja amplamente valorizado como condição para a inserção profissional, constatamos forte relativização da importância do conhecimento oferecido nos cursos superiores e críticas ao modo como se estruturam, considerado ultrapassado. A formação universitária não parece estar suprindo as expectativas dos entrevistados em termos de obtenção de conhecimento, tampouco no que diz respeito à instrumentalização para as demandas do mundo do trabalho.

Chama a atenção o fato de que, embora não se possa negar a multiplicidade de possibilidades no que tange à escolha de um futuro profissional, tal diversidade não se traduz, para os jovens entrevistados, em uma variedade de projetos profissionais que reflitam grande homogeneidade das aspirações, bem como das estratégias para a inserção. Assim como salientado por Valore e Selig (2010), a sujeição à mercantilização das práticas sociais, bem como dos modos de subjetivação, exercem intensa homogeneização da subjetividade. O habitus de classe marcou de maneira importante as narrativas analisadas. Segundo Bourdieu (2007), há uma homogeneidade relativa ao habitus, resultante das condições de existência de um grupo ou classe. Tal homogeneidade causa uma identidade de práticas, conferindo-lhes regularidade, além de serem vivenciadas como evidentes, necessárias, inteligíveis e previsíveis, ainda que sejam retrato apenas de determinado grupo.

Consideramos que o presente trabalho descortina atravessamentos presentes no processo de inserção profissional, tais como o contexto socioeconômico no qual o jovem está inserido, valores e significados relacionados ao trabalho, bem como o modo como os jovens traduzem em ação suas expectativas em relação ao futuro profissional. Entendemos que todos os envolvidos com a temática da inserção profissional devem estar atentos às exigências provenientes da nova configuração do trabalho, mais flexibilizado, globalizado e competitivo. É por meio da análise crítica deste recente contexto que se poderá chegar à compreensão dos atravessamentos nele presentes. Neste estudo, as falas dos jovens entrevistados sugerem um cenário marcado pela cultura do desempenho, da competição exacerbada e da produtividade, ideais do empresariado que avançam sobre as vidas particulares, ocupando todas as esferas biográficas dos indivíduos. 


\section{Referências}

Antunes, R. (1999). O mundo precarizado do trabalho e seus significados. Cadernos de Psicologia Social do Trabalho, 2(1), 55-72.

Antunes, R. (2005). O Caracol e Sua Concha: ensaios sobre a nova 'morfologia do trabalho'. São Paulo: Boitempo Editorial, 2005.

Bajoit, G., Franssen., A. (2007). O trabalho, busca de sentido. In: Fávero, O., Spósito, M. P., Carrano, P., Novaes, R. R. (Orgs.). Juventude e contemporaneidade (pp. 93-123). Brasília: UNESCO.

Bourdieu, P. (2007). A Distinção: crítica social do julgamento. São Paulo: Edusp; Porto Alegre: Zouk.

Carreteiro, T. C. (2007) Famílias confrontadas com o trabalho futuro dos filhos - um projeto de pesquisa. In FéresCarneiro, T. (Org.). Família e casal: saúde, trabalho e modos de vinculação (pp. 181-201). São Paulo: Casa do Psicólogo.

Castro, L. R. (2011) Os jovens podem falar? Sobre as possibilidades políticas de ser jovem hoje. In: Moreira, M. I. C.; Dayrrell, J. (Org.). Juventudes Contemporâneas: um mosaico de possibilidades (299-324). Belo Horizonte: Puc Minas.

Corrochano, M.C. (2008). O trabalho e a sua ausência: narrativas de jovens do Programa Bolsa Trabalho no município de São Paulo. Tese de Doutorado, Faculdade de Educação, Universidade de São Paulo, São Paulo.

Gaulejac, V. (2007). Gestão como doença social: ideologia, poder gerencialista e fragmentação social. Aparecida: Ideias e Letras.

Giroto Guedes, V. (2007) Trajetórias juvenis: o trabalho como valor, o valor do trabalho. Tese de Doutorado, Instituto de Psicologia, Universidade Federal do Rio de Janeiro, Rio de Janeiro.

Guimarães, N. A. (2006). Trajetórias inseguras, autonomização incerta: os jovens e o trabalho em mercados sob intensas transições ocupacionais. In: Camarano, A. A. Transição para a vida adulta ou vida adulta em transição. Rio de Janeiro: Ipea.

Instituto Brasileiro de Análises Sociais e Econômicas. (2005). Juventude brasileira e democracia: participação, esferas e políticas públicas. Rio de Janeiro: Poli Ibases.

Korman Dib, S. (2007). Juventude e projeto profissional: a construção subjetiva do trabalho. Tese de Doutorado, Programa de Pós-Graduação em Psicologia, Universidade Federal do Rio de Janeiro, Rio de Janeiro.

Korman Dib, S., Dias, C. (2004). Inserção profissional dos jovens: o empreendedorismo e as formas de participação. Anais da III Conferência Internacional de Pesquisa em Empreendedorismo na América Latina, Rio de Janeiro.

Juncken, E. T. (2005) Juventude pobre, participação e redes de sociabilidade na construção do projeto de vida. Dissertação de Mestrado, Instituto de Psicologia, Universidade Federal do Rio de Janeiro, Rio de Janeiro.

Malvezzi, S. (1999). Empregabilidade e carreira. Cadernos de Psicologia Social do Trabalho, 1, 68-72.

Minayo, S. C. M. (2004). O desafio do conhecimento: pesquisa qualitativa em saúde (8a ed.). São Paulo: Hucitec.

Monteiro, R. (2011). A transição para a vida adulta no contemporâneo: um estudo com jovens cariocas e quebequenses. Tese de Doutorado, Programa de Pós-Graduação em Psicologia, Universidade Federal do Rio de Janeiro, Rio de Janeiro.

Neves, T. F. S. (2006). Ensaios sobre o desemprego: qualidades de um "novo" trabalhador? Imaginário, São Paulo, 12(13), 123-141.

Oliveira, L. B. (2011). Percepções e estratégias de inserção no trabalho de universitários de Administração. Revista Brasileira de Orientação Profissional, 12(1), 83-95.

Pochmann, M. (2012). Nova formação para o trabalho imaterial. Revista Fórum. Mar. 2012. Recuperado em 7 de outubro, 2012, de <http://marciopochmann.com.br/artigos/nova-formacao-para-o-trabalho-imaterial>.

Porto, J. B., \& Tamayo, A. (2003). Escala de Valores Relativos ao Trabalho - EVT. Psicologia: Teoria e Pesquisa, 19(2), 145-152.

Ribeiro, M. A. (2010). A influência psicossocial da família e da escola no projeto de vida no trabalho dos jovens. Pesquisas e Práticas Psicossociais, 5(1), 120-130. 
Tanguy, L. (1999) Do sistema educativo ao emprego. Formação: um bem universal? Educação Eु Sociedade, São Paulo: Papirus, 20(67), 48-69.

Thome, L. D., Telmo, A. Q., \& Koller, S. H. (2010). Inserção laboral juvenil: contexto e opinião sobre definições de trabalho. Paidéia, Ribeirão Preto, 20(46), 175-185.

Tolfo, S. R. (2002). A carreira profissional e seus movimentos: revendo conceitos e formas de gestão em tempos de mudanças. Revista Psicologia: Organizações e Trabalho, 2(2), 39-63.

Valore, L. A., Selig, G. A. (2010). Inserção Profissional de recém-graduados em tempos de inseguranças e incertezas. Estudos e Pesquisas em Psicologia. UERJ, Rio de Janeiro, 10(2), 390-404.

Waiselfisz, J. J. (2007). Relatório de desenvolvimento juvenil. Brasília: Rede de Informação Tecnológica Latino-Americana.

\section{Endereço para correspondência}

psicomarina@gmail.com,lrcastro@infolink.com.br
Recebido em: 21/02/2014

Revisado em: 25/11/2014

Aprovado em: 16/12/2014 